05

\title{
Влияние кристаллизующего отжига под нагрузкой на магнитные свойства и структуру магнитомягкого сплава FeSiNbCuB, легированного хромом
}

\author{
(C) Н.В. Ершов ${ }^{1}$, В.И. Федоров ${ }^{2}$, Ю.П. Черненков ${ }^{2}$, В.А. Лукшина ${ }^{1,3}$, Д.А. Шишкин ${ }^{1,3}$ \\ ${ }^{1}$ Институт фризики металлов УрО РАН, \\ Екатеринбург, Россия \\ 2 Петербургский институт ядерной фризики, НИЦ „Курчатовский институт“, \\ Гатчина, Россия \\ ${ }^{3}$ Уральский фредеральный университет им. Б.Н. Ельцина, \\ Екатеринбург, Россия \\ E-mail: nershov@imp.uran.ru
}

(Поступила в Редакцию 15 марта 2017 г.)

С целью выяснения влияния термомеханической обработки (ТМехО), состоящей в отжиге и охлаждении образцов сплава под действием растягивающего напряжения, на магнитные свойства и структуру сплавов $\mathrm{Fe}_{73.5} \mathrm{Si}_{13.5} \mathrm{~B}_{9} \mathrm{Nb}_{3} \mathrm{Cu}_{1}$, легированных до 10 at.\% хромом за счет железа, проведен анализ изменений квазистатических петель магнитного гистерезиса и рентгеновских дифрактограмм этих сплавов. Показано, что результатом ТМехО является наведение магнитной анизотропии типа „жесткая ось“, при которой затрудняется перемагничивание вдоль оси приложения внешнего напряжения при отжиге. По мере увеличения содержания хрома энергия наведенной магнитной анизотропии понижается. В процессе ТМехО возникает деформация решетки нанокристаллов, которая сохраняется после охлаждения. Межплоскостные расстояния увеличиваются вдоль направления растяжения и уменьшаются в поперечном направлении. Наблюдается анизотропия деформаций по кристаллографическим направлениям. Анизотропная деформация ОЦК-решетки нанокристаллов, содержащих большое количество упорядоченной $\mathrm{Fe}_{3} \mathrm{Si}$ фазы, характеризующейся отрицательным магнитоупругим взаимодействием, является причиной формирования состояния с поперечной магнитной анизотропией типа „жесткая ось“.

Работа выполнена в рамках государственного задания ФАНО России (тема „Магнит“, № 01201463328) при частичной поддержке УрО РАН (проект № 15-9-2-33).

DOI: 10.21883/FTT.2017.09.44843.078

\section{1. Введение}

Нанокристаллические сплавы в силу своих высоких магнитных свойств получили широкое применение в технике. Наиболее известен и исследован магнитомягкий нанокристаллический сплав $\mathrm{Fe}_{73.5} \mathrm{Si}_{13.5} \mathrm{~B}_{9} \mathrm{Nb}_{3} \mathrm{Cu}_{1}$ (Finemet - файнмет), созданный в Японии в конце 1980-х [1]. В настоящее время за счет изменения его состава и включения дополнительных элементов создаются новые сплавы с новыми функциональными возможностями.

Так, например, добавление хрома повышает устойчивость материала к коррозии и повышенным температурам [2]. Изменение состава меняет структуру и свойства материала, что необходимо дополнительно исследовать и тщательно контролировать. В работе [3] обнаружено, что добавление хрома в классический состав приводит к повышению температуры кристаллизации сплава из аморфного в нанокристаллическое состояние. Так, если в [1] интервал первичной нанокристаллизации сплава Finemet составляет $510-590^{\circ} \mathrm{C}$, то добавление в состав 1-5\% хрома по данным DTA постепенно увеличивает этот температурный интервал до $569-732^{\circ} \mathrm{C}$ при скорости нагрева $20 \mathrm{deg} / \mathrm{min}$ [3].
Структурные исследования, проведенные в работе [4], показали, что в нанокристаллическом состоянии после отжига при $520^{\circ} \mathrm{C}$ в течение двух часов все сплавы $\mathrm{Fe}_{73.5-X} \mathrm{Cr}_{X} \mathrm{Si}_{13.5} \mathrm{~B}_{9} \mathrm{Nb}_{3} \mathrm{Cu}_{1} \quad(X=0,1,2,3,5)$ содержали, в основном, зерна твердого раствора размером $10-12 \mathrm{~nm}$ с остатками аморфной фазы по их границам. В работе [5] было показано на образцах этих же составов, что добавка хрома за счет железа приводит к уменьшению максимальной намагниченности (в поле до $8 \mathrm{kA} / \mathrm{m})$ с 1.25 до $0.88 \mathrm{~T}$ при изменении содержания хрома от 0 до 5\% соответственно. При содержании хрома $1-3 \%$ коэрцитивная сила оставалась в пределах $2-4 \mathrm{~A} / \mathrm{m}$ и возрастала до $23 \mathrm{~A} / \mathrm{m}$ при 5\% хрома.

Термомеханическая обработка (отжиг и охлаждение под растягивающей нагрузкой - ТМехО) приводила во всех образцах указанных составов к наведению поперечной магнитной анизотропии (типа „жесткая ось“), после обработки петли гистерезиса из вертикальных становились наклонными и оставались линейными [6]. В работе [7] на нанокристаллических образцах $\mathrm{Fe}_{73.5-X} \mathrm{Cr}_{X} \mathrm{Si}_{13.5} \mathrm{~B}_{9} \mathrm{Nb}_{3} \mathrm{Cu}_{1}(X=0-4)$ наблюдалась доменная структура после отжига под растягивающей нагрузкой и без нее. Если на закристаллизованных 
без растяжения образцах $(X<3)$ доменная структура была полосовой продольной (вдоль длинной стороны образца), то после ТМехО доменная структура перестраивалась и становилась полосовой поперечной (поперек длинной стороны образца), что свидетельствовало о перераспределении намагниченности в образцах. Для образцов с $X \geq 3$ картина менялась на противоположную. Если после отжига без растяжения доменная структура была поперечной, то после ТМехО она становилась продольной. Петли гистерезиса в [7] всегда имели Zобразную форму. При $X<3$ после ТМехО вертикальная часть петли уменьшалась. При $X \geq 3$ отжиг под растяжением приводил к увеличению вертикальной части петли, что соответствует поведению доменной структуры на данных образцах.

Сравнивая результаты влияния отжига под нагрузкой в [5] и [7] на петли гистерезиса, видим, что в [5] в отличие от [7] на образцах с 3 и 5\% хрома после ТМехО петли из вертикальных становились наклонными, то есть наводилась поперечная направлению растяжения анизотропия. В [7], к сожалению, не проводилось исследование структуры материала. Вполне вероятно, что какие-то неустановленные особенности в структуре конкретных образцов могли обусловить и Z-образную форму петель гистерезиса, и смену характера наведенной анизотропии при $X \geq 3$.

Ранее было показано, что основной причиной появления анизотропии магнитных свойств в нанокристаллических сплавах на основе Finemet сплава после ТМехО является остаточная деформация решетки нанокристаллов [8-13]. В работе [14] было впервые установлено, что при увеличении содержания кремния от 0 до 13.5\% происходит изменение типа наводимой при отжиге под нагрузкой магнитной анизотропии. Если при концентрации $\mathrm{Si}$ до $\sim 9 \%$ в результате ТМехО наводится продольная магнитная анизотропия, то после $11 \%$ кремния - поперечная. Детальные исследования структуры нанокристаллов показали [12], что независимо от содержания кремния после ТМехО в ОЦК-решетке $\mathrm{Fe}(\mathrm{Si})$ нанокристаллов имеется остаточная деформация. Решетка растянута вдоль направления приложения нагрузки при отжиге и сжата в поперечном направлении. При этом изменение межплоскостного расстояния заметно различается для разных кристаллографических направлений: наибольшие деформации наблюдаются вдоль осей типа $\langle 100\rangle$. Растяжения и сжатия уменьшаются по мере уменьшения угла между направлением $[h k l]$ и ближайшей осью $\langle 111\rangle$. Наименьшие деформации межплоскостных расстояний фиксируются для плоскостей (111), их величина не превосходит величину погрешности измерений.

Магнитная анизотропия возникает в результате магнитоупругого взаимодействия, потому что намагниченность в нанокристаллах выстраивается вдоль или поперек направления приложения нагрузки при отжиге в зависимости от знака константы магнитоупругого взаимодействия в нанокристаллах, который полностью определяется объемной долей в них упорядоченной фазы $\mathrm{Fe}_{3} \mathrm{Si}$ [12]. Если неупорядоченный железокремнистый сплав характеризуется положительной константой магнитоупругого взаимодействия, то $\mathrm{Fe}_{3} \mathrm{Si}$-фаза - отрицательной. Поэтому в соответствии с эффектом Виллари, обратным эффекту магнитострикции, в отсутствии $\mathrm{Fe}_{3} \mathrm{Si}$-фазы намагниченность в нанокристаллах будет ориентироваться вдоль оси наибольшего растяжения решетки, т.е. формируется продольная (осевая) магнитная анизотропия. По мере увеличения концентрации кремния в нанокристаллах появляются и увеличиваются в объеме области с $\mathrm{Fe}_{3} \mathrm{Si}$ упорядочением. По данным работы [12] при средней концентрации кремния в сплаве

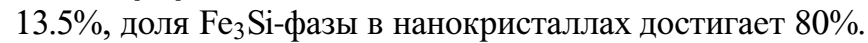
Меняется характер магнитной анизотропии, наводимой при ТМехО. Она становится поперечной или магнитной анизотропией типа „жесткая ось“.

Цель настоящей работы - исследовать влияние нанокристаллизующего отжига под действием растягивающей нагрузки на магнитные свойства и структуру сплавов $\mathrm{FeSiNbCuB}$, легированных до 10\% хромом за счет железа, провести анализ данных, полученных в магнитных и рентгено-дифракционных измерениях, выяснить влияние термической обработки под нагрузкой и без нее, установить корреляцию структуры и магнитных свойств, их зависимость от концентрации хрома.

\section{2. Образцы и методика эксперимента}

Исследуемые сплавы $\mathrm{Fe}_{73.5-X} \mathrm{Cr}_{X} \mathrm{Si}_{13.5} \mathrm{~B}_{9} \mathrm{Nb}_{3} \mathrm{Cu}_{1}$ $(X=0,1,2,3,5,7$ и 10) в виде аморфных лент толщиной 15-20 mcm, шириной 0.5-1 mm были получены методом закалки из расплава на вращающийся барабан. Нанокристаллизация образцов сплавов осуществлялась на воздухе при температуре $520^{\circ} \mathrm{C}$ в течение $2 \mathrm{~h}$ как в присутствии приложенного к ним эффективного растягивающего напряжения $160 \mathrm{MPa}$ (термомеханическая обработка - TMexO, tensile stress-annealing (TSA)), так и без него (нанокристаллизующий отжиг - HO, nanocrystallising-annealing (NCA)).

Для проведения ТМехО образцы длиной около $300 \mathrm{~mm}$ вертикально подвешивались в холодной трубчатой печи. К нижнему концу ленты прицеплялся груз $P$, вес которого рассчитывался по формуле: $P=\sigma \cdot S$, где $\sigma$ - заранее заданное механическое напряжение, $S$ поперечное сечение образца. Поскольку в процессе ТМехО образцы удлиняются, поперечное сечение уменьшается, то эффективное значение напряжения рассчитывалось с учетом уменьшения величины сечения после отжига под нагрузкой.

После включения питания печи заданная температура отжига достигалась примерно за $6 \mathrm{~min}$. С этого момента начинался отсчет продолжительности отжига. Последующее охлаждение образцов всегда проводилось с печью, а при ТМехО - еще и в присутствии приложенных к 
ним растягивающих напряжений. После охлаждения до комнатной температуры груз снимался.

Магнитное состояние полосовых образцов длиной $80 \mathrm{~mm}$ контролировалось по петлям гистерезиса, измеренным в открытой магнитной цепи с помощью гальванометрического компенсационного микровеберметра. Из петель гистерезиса, снятых в полях \pm 8000 A/m, приложенных вдоль оси ленты, определялись коэрцитивная сила $H_{c}$, максимальная и остаточная намагниченности, $B_{m}$ и $B_{r}$, максимальная магнитная проницаемость $\mu_{\max }$, поле насыщения $H_{s}$, в котором намагниченность практически достигает насыщения (кривая достигает своего горизонтального участка). Константа наведенной магнитной анизотропии в общем случае соответствует площади между кривыми намагничивания после НО и ТМехО. Для образцов с 0-5\% хрома, с узкими прямолинейными петлями гистерезиса, практически вертикальными после $\mathrm{HO}$ и наклонными после ТМехО, константа наведенной магнитной анизотропии $K_{u}$ рассчитывалась по формуле

$$
K_{u}=-0.5 \cdot 10^{4} \times B_{m} \times H_{s},
$$

где $B_{m}$ в $\mathrm{T}$, а $H_{s}$ в $\mathrm{A} / \mathrm{m}$. Равенство (1) определяет площадь треугольника между вертикальной осью намагниченности и осью наклона петли гистерезиса. Погрешности измерений магнитных свойств составляли: $\pm 3 \%$ для $H_{c}, \pm 7 \%$ для $B_{m}, B_{r}$ и $H_{s}, \pm 15 \%$ для $\mu_{\max }$ и $\pm 10 \%$ для $K_{u}$.

Для рентгенодифракционных исследований были приготовлены образцы из фрагментов лент длиной 8-9 mm, которые наклеивались на оправки, имеющие форму тонких и узких колец, параллельно друг другу в несколько перекрывающихся слоев толщиной $\sim 40-50 \mathrm{mcm}$. Дифрактограммы измерялись на четырехкружном рентгеновском дифрактометре (ПИЯФ НИЦ „Курчатовский институт“) в геометрии на просвет с использованием монохроматизированного рентгеновского излучения $\left(\mathrm{Mo} K_{\alpha}, \quad \lambda=0.71 \AA\right)$. Схема эксперимента приведена в $[8,9]$. При сканировании вектор рассеяния все время оставался в плоскости образца и мог быть ориентирован вдоль или поперек оси ленты вращением образца на угол $90^{\circ}$. Для каждого образца $\theta-2 \theta$-сканированием были получены две дифрактограммы, измеренные вдоль и поперек ленты, т.е. параллельно и перпендикулярно направлению приложения растягивающей нагрузки при TMехО. В дифрактограммах в интервале $2 \theta$ углов от 15 до $60^{\circ}$ наблюдаются пики с миллеровскими индексами (110), (200), (211), (220), (310), (222) и (321), разрешенные для объемно-центрированной кубической (ОЦК) решетки $\alpha$-Fe( $\mathrm{Si})$. Кроме того, в дифрактограммах образцов сплава $\mathrm{Fe}-\mathrm{Si}-\mathrm{Nb}-\mathrm{Cu}-\mathrm{B}$ с добавлением хрома могут присутствовать сверхструктурные рефлексы от упорядоченной фазы $\mathrm{Fe}_{3} \mathrm{Si}$ (структура $D 0_{3}$ ), которые обычно появляются при концентрации кремния более 11 at.\% [8].

Из положений пиков $(h k l)$ на дифрактограмме, которые определяются из ее профильного анализа методом наименьших квадратов [12], вычисляются соответствующие межплоскостные расстояния $d_{h k l}$. Таким образом из дифрактограмм образцов, прошедших ТМехО, можно определить деформации растяжения, если анализировать дифрактограмму, измеренную при сканировании вдоль ленты. Из дифрактограмм, измеренных при поперечном сканировании, можно определить сжатия. Относительные деформации $\varepsilon_{h k l}$ вычисляются из сопоставления межплоскостных расстояний после ТМехО $-d_{h k l}^{\text {TSA }}$ с межплоскостными расстояниями в образцах, не подвергнутых при отжиге растягивающему напряжению $d_{h k l}^{\mathrm{NCA}}$, по формуле

$$
\varepsilon_{h k l}=\frac{d_{h k l}^{\mathrm{TSA}}-d_{h k l}^{N C A}}{d_{h k l}^{\mathrm{NCA}}} .
$$

Фазовый анализ дифрактограмм не дает надежных количественных результатов из-за небольшого числа пиков на дифрактограмме, но он позволяет получить грубую оценку массовых долей кристаллической и аморфной фаз. Таким способом, в принципе, может быть исследована зависимость фазового состава (или хотя бы тенденция изменения фазового состава) от концентрации хрома, от температуры и продолжительности отжига и от других условий термической обработки.

\section{3. Результаты и обсуждение}

В работе [5] было исследовано влияние термомеханической обработки растяжением в процессе нанокристаллизующего отжига на поведение магнитных свойств образцов Finemet сплава с замещением хромом до $5 \%$ железа. Термообработка проводилась при $520^{\circ} \mathrm{C}$ в течение $2 \mathrm{~h}$. Для всех составов было обнаружено существенное изменение петли гистерезиса и магнитных свойств после ТМехО, соответствующих наведению поперечной магнитной анизотропии типа жесткая ось. В настоящей работе это же исследование проведено для образцов сплавов $\mathrm{Fe}_{73.5-X} \mathrm{Cr}_{X} \mathrm{Si}_{13.5} \mathrm{~B}_{9} \mathrm{Nb}_{3} \mathrm{Cu}_{1}$ с содержанием хрома $X=7$ и 10 . Чтобы сравнить результаты исследований для сплавов от $X=0$ до 10, условия термообработок были такими же, как в работе [5]. На рис. $1, a-g$ показаны петли магнитного гистерезиса после нанокристаллизации под нагрузкой (TSA) и без нее (NCA) для образцов с содержанием хрома $X=0$, $1,2,3,5,7$ и 10. Эффект ТМехО наблюдается для всех $X$. После ТМехО петли гистерезиса становятся наклонными.

Кроме того, с увеличением $X$ уменьшается намагниченность в больших магнитных полях, максимальная намагниченность $-B_{m}$, и увеличивается ширина петель при $B=0 \mathrm{~T}$, т. е. растет коэрцитивная сила $-H_{c}$. Параметры $B_{m}, B_{r}, H_{c}, \mu_{\max }, H_{s}$ и $K_{u}$, которые характеризуют магнитные свойства и определены из петель гистерезиса для всех составов после НО и ТМехО, приведены в табл. 1. Кроме того, в столбце 8 приведены значения 

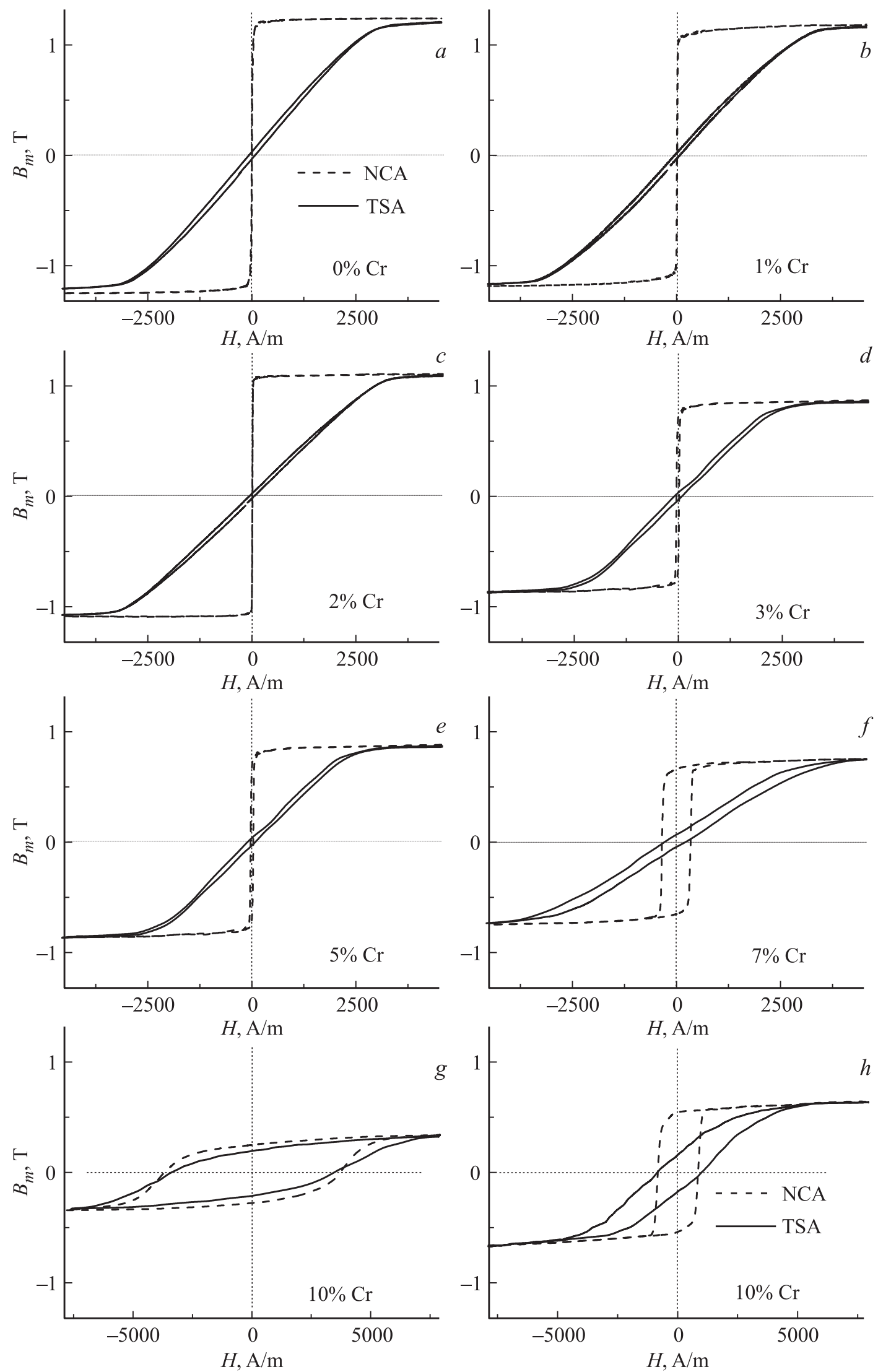

Рис. 1. Петли гистерезиса образцов после кристаллизующего отжига под действием растягивающей нагрузки TSA (сплошные линии) и без нее $\mathrm{NCA}\left(\right.$ штриховые) при температуре $520^{\circ} \mathrm{C}$ в течение $120 \mathrm{~min}$ с содержанием хрома $X=0,1,2,3,4,5,7$ и $10-a, b, c, d, e, f$ и $g$ соответственно; $h$ - аналогичные петли образца с $10 \%$ хрома после отжигов при температуре $600^{\circ} \mathrm{C}-$ $30 \mathrm{~min}$. 
Таблица 1. Параметры, характеризующие магнитные свойства исследованных сплавов $\left(C_{\mathrm{Cr}}=0-10\right.$ at.\%) после нанокристаллизующего отжига без внешних воздействий $(\mathrm{HO})$ и в присутствии растягивающей нагрузки (ТМехО)

\begin{tabular}{|c|c|c|c|c|c|c|c|c|}
\hline Обработка & $C_{\mathrm{Cr}}$, at. $\%$ & $B_{m}, \mathrm{~T}$ & $H_{c}, \mathrm{~A} / \mathrm{m}$ & $B_{r}, \mathrm{~T}$ & $\mu_{\max }$ & $H_{s}, \mathrm{~A} / \mathrm{m}$ & $-\Delta, \mathrm{J} / \mathrm{m}^{3}$ & $-K_{u}, \mathrm{~J} / \mathrm{m}^{3}$ \\
\hline $\begin{array}{c}\mathrm{HO} \\
520^{\circ} 120 \mathrm{~min}\end{array}$ & $\begin{array}{r}0 \\
1 \\
2 \\
3 \\
5 \\
7 \\
10\end{array}$ & $\begin{array}{l}1.24 \\
1.19 \\
1.11 \\
0.98 \\
0.87 \\
0.77 \\
0.34\end{array}$ & $\begin{array}{c}3.3 \\
4.4 \\
2.2 \\
4.9 \\
23 \\
340 \\
3700\end{array}$ & $\begin{array}{l}0.28 \\
0.38 \\
0.23 \\
0.25 \\
0.77 \\
0.64 \\
0.26\end{array}$ & $\begin{array}{r}45000 \\
32000 \\
40000 \\
44000 \\
42000 \\
13000 \\
200\end{array}$ & $\begin{array}{r}18 \\
15 \\
28 \\
30 \\
39 \\
35 \\
1240\end{array}$ & $\begin{array}{r}15 \\
11 \\
11 \\
10 \\
31 \\
140 \\
210\end{array}$ & $\begin{array}{l}- \\
- \\
- \\
- \\
- \\
- \\
-\end{array}$ \\
\hline $\begin{array}{c}\mathrm{HO} \\
600^{\circ} \mathrm{C} 30 \mathrm{~min}\end{array}$ & 10 & 0.6 & 840 & 0.53 & 2530 & 1000 & 280 & - \\
\hline $\begin{array}{c}\mathrm{TMexO} \\
520^{\circ} \mathrm{C} 120 \mathrm{~min} \\
160 \mathrm{MPa}\end{array}$ & $\begin{array}{r}0 \\
1 \\
2 \\
3 \\
5 \\
7 \\
10\end{array}$ & $\begin{array}{l}1.24 \\
1.18 \\
1.09 \\
0.97 \\
0.88 \\
0.77 \\
0.32\end{array}$ & $\begin{array}{r}71 \\
60 \\
58 \\
86 \\
93 \\
254 \\
3400\end{array}$ & $\begin{array}{l}0.032 \\
0.027 \\
0.023 \\
0.028 \\
0.034 \\
0.06 \\
0.20\end{array}$ & $\begin{array}{r}850 \\
850 \\
760 \\
670 \\
300 \\
180 \\
90\end{array}$ & $\begin{array}{l}2800 \\
2900 \\
3000 \\
3000 \\
2400 \\
3100 \\
2400\end{array}$ & $\begin{array}{r}1700 \\
1710 \\
1650 \\
1460 \\
1070 \\
1100 \\
390\end{array}$ & $\begin{array}{r}1685 \\
1700 \\
1640 \\
1450 \\
1040 \\
960 \\
180\end{array}$ \\
\hline $\begin{array}{c}\text { TMexO } \\
600^{\circ} \mathrm{C} 30 \mathrm{~min} \\
160 \mathrm{MPa}\end{array}$ & 10 & 0.6 & 930 & 0.15 & 150 & 4100 & 1230 & 950 \\
\hline
\end{tabular}

вспомогательной величины $\Delta$, значение которой будет объяснено ниже.

Максимальная индукция значительно уменьшается по мере увеличения содержания немагнитного хрома в образцах сплава, причем в пределах погрешности измерений зависимость от условий термообработки (под нагрузкой или без нее) не наблюдается. Резкое падение $B_{m}$ между $X=7$ и 10 , возможно, объясняется повышением температуры кристаллизации файнмет сплавов при легировании хромом и связано с тем, что при отжиге температура $520^{\circ} \mathrm{C}$ недостаточна для полной нанокристаллизации сплава. В пользу этого свидетельствует то, что $B_{m}=0.6 \mathrm{~T}$ при $X=10$ (точка показана на рис. 2) для образцов после отжига при температуре $600^{\circ} \mathrm{C}$ в течение $30 \mathrm{~min}$ (табл. 1).

В отличие от результатов работы [7] здесь наблюдается значительное влияние нагрузки, приложенной во время отжига, на вид петель гистерезиса (рис. 1), а также на их магнитные свойства. В табл. 1 (столбец 4) видно, что после нанокристаллизации при $520^{\circ} \mathrm{C}$ без внешних воздействий (после $\mathrm{HO}$ ) коэрцитивная сила $H_{c}$ для сплавов с $X=0-3$ составляет $(2.2-4.9) \mathrm{A} / \mathrm{m}$, для сплава с $X=5$ становится существенно больше $23 \mathrm{~A} / \mathrm{m}$, для образцов с 7 и $10 \%$ хрома $H_{c}$ возрастает по сравнению с 5\% на один и два порядка соответственно. В результате ТМехО $H_{c}$ возросла по сравнению с $\mathrm{HO}$ и составила $(58-93) \mathrm{A} / \mathrm{m}$ для $0-5 \% \mathrm{Cr}$, для 7 и $10 \%$ хрома $H_{c}$ после ТМехО, как и после ТО, составила сотни и тысячи $\mathrm{A} / \mathrm{m}$ соответственно. Зависимость коэрцитивной силы от содержания хрома после $\mathrm{HO}$ и ТМехО проиллюстрирована на рис. 3.
По данным просвечивающей электронной микроскопии [4] в образцах с $X=0-5$ средний размер зерна не изменяется и составляет примерно 10-12 nm. Но, начиная с $3 \% \mathrm{Cr}$, наблюдаются и мелкие зерна размером 1-2 nm. В работе [4] было сделано предположение, что это выпадения хрома или зародыши новой фазы с повышенным содержанием хрома. Возможно, что появление этих немагнитных включений приводит к повышению

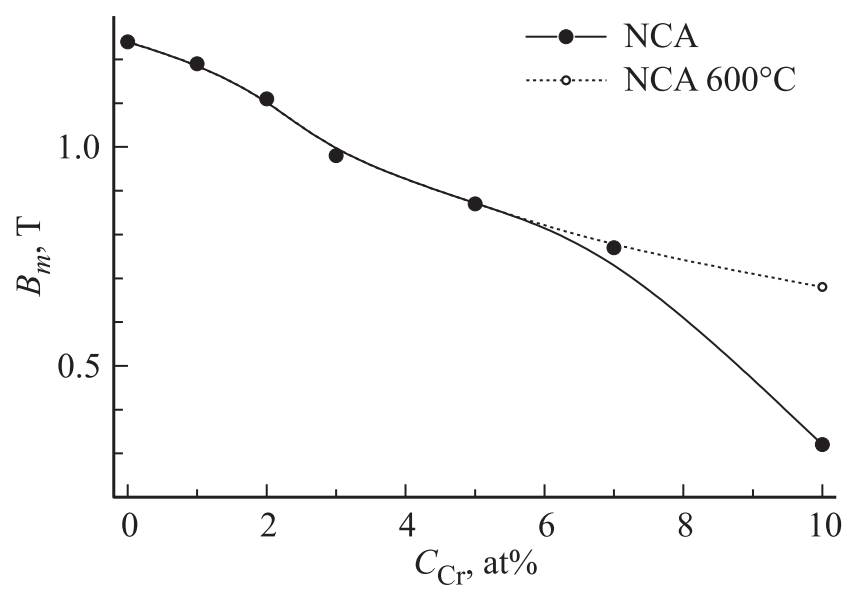

Рис. 2. Зависимость наибольшей индукции, $B_{m}$, наблюдаемой в петлях гистерезиса, от концентрации хрома в сплаве для образцов, отожженных без внешних воздействий (NCA). Пунктиром показана предполагаемая тенденция изменения $B_{m}$ от $C_{\mathrm{Cr}}=5-7$ к значению $B_{m}$ при $C_{\mathrm{Cr}}=10 \%$, полученному в результате отжига при температуре $600^{\circ} \mathrm{C}$ в течение $30 \mathrm{~min}$. 


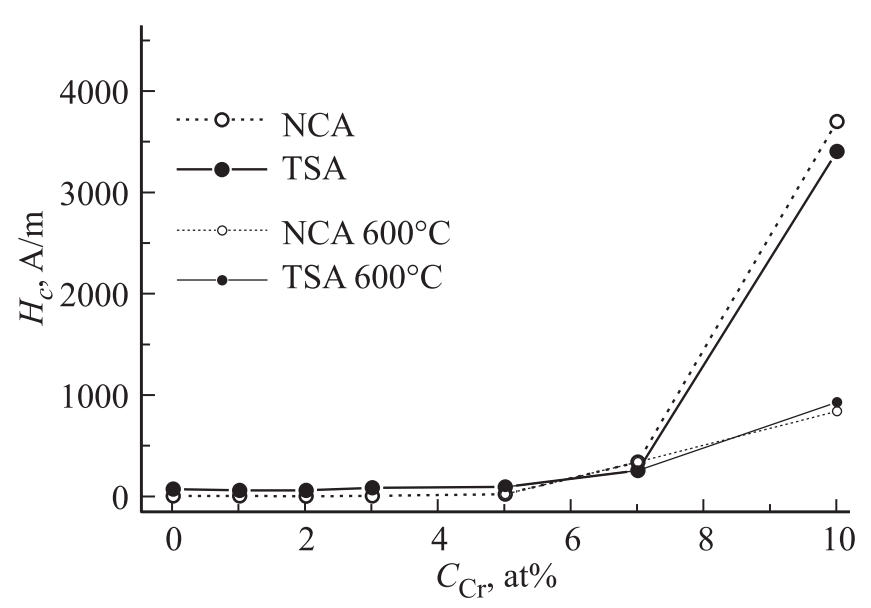

Рис. 3. Зависимость коэрцитивной силы, $H_{c}$, наблюдаемой в петлях гистерезиса, от концентрации хрома в сплаве для образцов, отожженных без внешних воздействий (NCA) и под действием растягивающей нагрузки, создающей напряжение около $160 \mathrm{MPa}$ (TSA). Тонкими линиями показана предполагаемая тенденция изменения $H_{c}$ от $C_{\mathrm{cr}}=5-7$ к значениям $H_{c}$ при $C_{\mathrm{Cr}}=10 \%$, полученным в результате отжига при температуре $600^{\circ} \mathrm{C}$ в течение $30 \mathrm{~min}$.

коэрцитивной силы и понижению максимальной намагниченности [4].

После ТМехО при $520^{\circ} \mathrm{C}$, как показано на рис. 1 для образцов всех составов, петли гистерезиса стали наклонными, что соответствует уменьшению остаточной намагниченности $B_{r}$ примерно в 10 раз по сравнению с $B_{r}$ после НО (столбец 5 в табл. 1), уменьшению максимальной магнитной проницаемости с 45000-200 до 850-90 (столбец 6) и увеличению примерно на два порядка поля насыщения $H_{s}$ (столбец 7).

В столбце 8 табл. 1 приведены значения константы $\Delta$, которая характеризует отклонение петли гистерезиса от вертикальной оси и рассчитывается по формуле (1), если положить, что $\Delta=K_{u}$. По результатам магнитных измерений образцы с содержанием хрома $X=0-5$ после НО имеют петли гистерезиса с небольшим отклонением от вертикальной оси намагниченности $B$, поэтому для них $\Delta \approx-(10-30) \mathrm{J} / \mathrm{m}^{3}$ (табл. 1). Для образцов с 7 и $10 \%$ хрома петли гистерезиса, показанные на рис. $1, f, g$ и $h$ как NCA кривые, имеют довольно большой наклон относительно оси $B$ (столбец 8, табл. 1): $\Delta=-140$ и $-210 \mathrm{~J} / \mathrm{m}^{3}$ после отжига при $T=520^{\circ} \mathrm{C}$ соответственно и $\Delta=-280 \mathrm{~J} / \mathrm{m}^{3}$ после НО при $T=600^{\circ} \mathrm{C}$ в течение $30 \mathrm{~min}$. Величину $\Delta$ следует учитывать при получении оценки константы магнитной анизотропии $K_{u}$, наведенной в результате ТМехО, по формуле

$$
K_{u}=K_{u}^{T S A}-\Delta .
$$

Здесь $K_{u}^{\mathrm{TSA}}$ и $\Delta$ вычисляются по формуле (1) из параметров петли магнитного гистерезиса, измеренных после ТМехО и НО соответственно. Значения $K_{u}$ после ТМехО с учетом величины $\Delta$ приведены в столбце 9 табл. 1 .
На рис. 4 показан график зависимости $-K_{u}$ от $C_{\mathrm{Cr}}$ в сплаве. Эффект ТМехО при $T=520^{\circ} \mathrm{C}$ в течение $2 \mathrm{~h}$, оцениваемый по величине константы $K_{u}$, уменьшается по мере увеличения концентрации хрома с $-1700 \mathrm{~J} / \mathrm{m}^{3}$ при $X=0$ и 1 до $-180 \mathrm{~J} / \mathrm{m}^{3}$ при $X=10$, т. е. примерно на один порядок. Повышение температуры отжига образца сплава с $10 \%$ хрома при ТМехО до $600^{\circ} \mathrm{C}$ позволяет получить $K_{u}=-950 \mathrm{~J} / \mathrm{m}^{3}$, близкое к его значению после ТМехО при $520^{\circ} \mathrm{C}$ в образце с $7 \%$ хрома. Поэтому резкое снижение эффекта ТМехО от 7 до 10 at.\% $\mathrm{Cr}$ скорее всего связано с неполной нанокристаллизацией образцов сплава, легированного $10 \%$ хрома, что в свою очередь вызвано резким увеличением температуры кристаллизации Finemet сплава при замене 10\% железа хромом [3].

Наклонный вид петель гистерезиса после ТМехО говорит о затруднении процессов перемагничивания вдоль ленты, вдоль направления приложения нагрузки во время отжига, что является результатом наведения поперечной магнитной анизотропии в процессе термомеханической обработки, и характерно для материалов с отрицательной константой магнитострикции. Надо заметить, что константу наведенной магнитной анизотропии в широких пределах можно изменять величиной нагрузки при ТМехО. Максимальное значение $K_{u}$, полученное в результате ТМехО в сплаве файнмет (без хрома), достигает $-12 \mathrm{~kJ} / \mathrm{m}^{3}$ [15].

Петли гистерезиса, измеренные на образцах с $10 \% \mathrm{Cr}$ после отжига при $520^{\circ} \mathrm{C}$ в течение $2 \mathrm{~h}$ с нагрузкой и без, приведены на рис. $1, g$. Обе петли имеют частный вид, так как в обоих случаях кривые не достигают своего насыщения в максимальном поле $\pm 8 \mathrm{kA} / \mathrm{m}$. Тем не менее, из рис. $1, g$ видно увеличение угла наклона

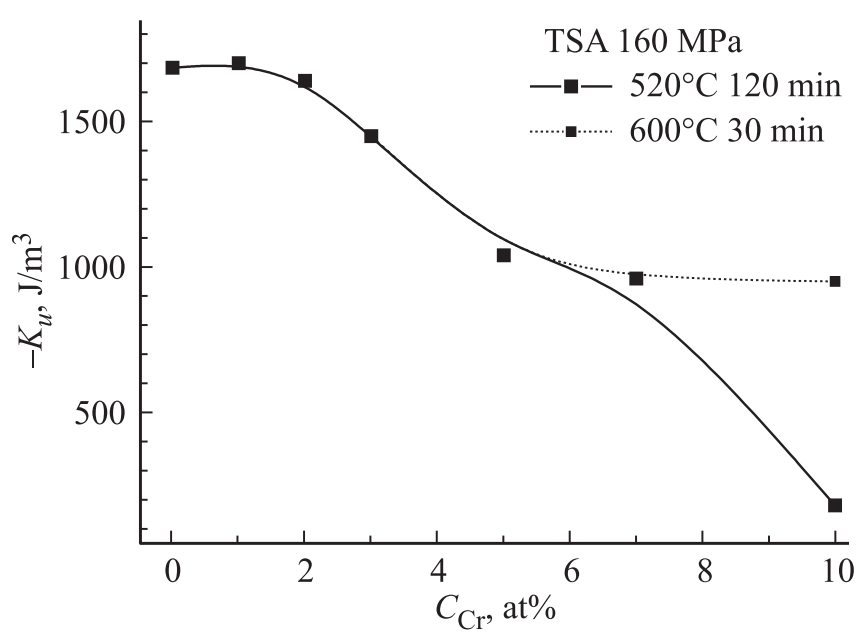

Рис. 4. Зависимость константы анизотропии, $-K_{u}$, полученной из петель гистерезиса, от концентрации хрома в сплаве для образцов, отожженных под действием растягивающей нагрузки, создающей напряжение около $160 \mathrm{MPa}$ (TSA). Пунктиром показана предполагаемая тенденция изменения $-K_{u}$ от $C_{\mathrm{Cr}}=5-7$ к значению $-K_{u}$ при $C_{\mathrm{Cr}}=10 \%$, полученному в результате отжига при температуре $600^{\circ} \mathrm{C}$ в течение $30 \mathrm{~min}$. 
петли у образца после ТМехО, а также уменьшение остаточной намагниченности и максимальной магнитной проницаемости (табл. 1), что свидетельствует о наведении поперечной анизотропии. Приведенное в табл. 1 значение $K_{u}$ справедливо только для данной частной петли магнитного гистерезиса.

По данным DTA температура кристаллизации сплава $\mathrm{Fe}_{73.5-X} \mathrm{Cr}_{X} \mathrm{Si}_{13.5} \mathrm{~B}_{9} \mathrm{Nb}_{3} \mathrm{Cu}_{1}$ с увеличением содержания хрома $X$ возрастает [3]. Это дает основание предположить, что для сплава с $10 \%$ хрома $2 \mathrm{~h}$ выдержки при $T=520^{\circ} \mathrm{C}$ недостаточно для завершения процессов кристаллизации. Для проверки этого предположения петли гистерезиса образцов сплава с $X=10$ были измерены после отжига при $600^{\circ} \mathrm{C}$ в течение $30 \mathrm{~min}$ $(\mathrm{HO}$ и ТМехО), рис. $1, h$. Видно, что петли выходят на насыщение в поле $1000 \mathrm{~A} / \mathrm{m}$ после НО и в поле $4100 \mathrm{~A} / \mathrm{m}$ после ТМехО. В результате увеличения температуры отжига максимальная намагниченность $B_{m}$ увеличилась почти в 2 раза, с 0.34 до $0.6 \mathrm{~T}$, коэрцитивная сила $H_{c}$ уменьшилась в несколько раз, с 3700 до $840 \mathrm{~A} / \mathrm{M}$ после НО и с 3400 до 930 А/м после ТМехО. Константа наведенной магнитной анизотропии $K_{u}$ в сплаве с $X=10$ после ТМехО при $600^{\circ} \mathrm{C}$ стала в пять раз больше, $-950 \mathrm{~J} / \mathrm{m}^{3}$ по сравнению с $-180 \mathrm{~J} / \mathrm{m}^{3}$ после ТМехО при $520^{\circ} \mathrm{C}$. Магнитные свойства сплава, полученные после термических обработок при повышенной температуре приведены в табл. 1 и на рис. 2-4.

Таким образом, изменение магнитных свойств сплавов при увеличении концентрации легирующего элемента хрома до 10 at.\% скорее всего связано с неполной нанокристаллизацией из исходного состояния, полученного закалкой из расплава. Магнитомягкие $\alpha$-FeSi нанокристаллы, образовавшиеся из аморфной фазы, обусловливают высокие магнитомягкие свойства сплава, поэтому уменьшение их объемной доли в сплаве после нанокристаллизующего отжига приводит к ухудшению магнитных свойств. Выяснение наиболее оптимальных условий нанокристаллизации сплавов с легирующими элементами несомненно будет предметом дальнейших исследований.

Рентгеновские дифрактограммы образцов сплавов в исходном состоянии, т. е. сразу после закалки из расплава на вращающееся колесо, показаны на рис. 5, где для сравнения приведена дифрактограмма от образца сплава $\mathrm{Fe}_{73.5} \mathrm{Si}_{13.5} \mathrm{Nb}_{3} \mathrm{Cu}_{1} \mathrm{~B}_{9}$, не содержащего хрома, которая взята из работы [12]. Из рисунка видно, что какихлибо значимых различий в распределении интенсивности рассеяния не наблюдается. При наложении все три дифрактограммы практически совпадают.

Дифрактограммы, приведенные на рис. 5, типичны для аморфных материалов, например, таких как металлические стекла [16]. Положение максимумов на дифрактограмме от сплава в исходном состоянии $\left(2 \theta \approx 20^{\circ}, 35^{\circ}\right.$, $40^{\circ}$ и $52^{\circ}$ ) совпадает с расчетным положением брэгговских рефлексов (110), (211), (220) и (222) для ОЦКжелеза. Поэтому можно сделать предположение, что в сплавах имеются небольшие области с ОЦК ближним

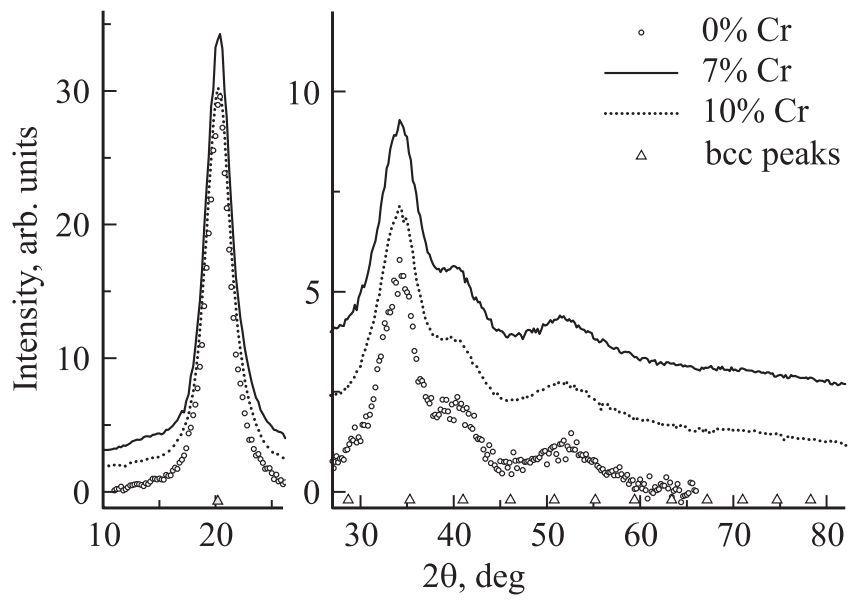

Рис. 5. Дифрактограммы образцов сплавов с разным содержанием хрома $(X=0,7$ и 10$)$, закаленных из расплава на медное колесо. Полыми треугольниками отмечены позиции разрешенных пиков от ОЦК-решетки железа, появление которых ожидается после кристаллизации нанокристаллов. В правой части дифрактограммы масштаб шкалы интенсивности увеличен в 3 раза для большей наглядности.

порядком. Если учесть, что при кратчайшем расстоянии между двумя атомами железа, равном $2.48 \AA$ в $\alpha$-Fe, положение основного пика в дифракционной картине от разупорядочено расположенных атомов железа должно быть $2 \theta_{\mathrm{am}}=16.5^{\circ}$ [17], то сплавы, дифрактограммы которых приведены на рис. 5, являются скорее локально упорядоченными, чем аморфными. Средний размер областей с ОЦК упорядочением, определяемый из интегральной ширины рефлекса с учетом инструментального разрешения, рассчитывается по формуле Шеррера [18], как это было сделано в работе [12]. Тогда структура сплавов в исходном состоянии может быть определена как мелкозернистая, сильно дефектная ОЦК структура с размером зерен около $2 \mathrm{~nm}$.

После отжига при температуре $520^{\circ} \mathrm{C}$ в течение $2 \mathrm{~h}$ на дифрактограммах образцов сплавов с $X=7$ и 10 появляются брэгговские пики от ОЦК-решетки нанокристаллов. На рис. 6 приведены дифрактограммы образцов после отжига под нагрузкой и без нее для сплава с 7 и $10 \%$ хрома. Дифрактограммы сплавов с одинаковым содержанием хрома, но разными термообработками очень похожи.

Под узкими брэгговскими пиками виден фон, состоящий из значительно более широких пиков, вклад в которые происходит преимущественно от аморфной матрицы. Согласно результатам более ранних исследований [19] матрица в основном состоит из боридов железа и ниобия, ее состав может быть записан как $\mathrm{Fe}(\mathrm{Nb})-\mathrm{B}$. Кроме основных пиков от $\mathrm{Fe}-\mathrm{Si}$ нанокристаллов заметный вклад в дифрактограмму дают области со сверхструктурным упорядочением, области фазы $\mathrm{Fe}_{3} \mathrm{Si}$ (структура $\mathrm{DO}_{3}$ ). В работе [12] было показано, что для возникновения поперечной магнитной анизо- 

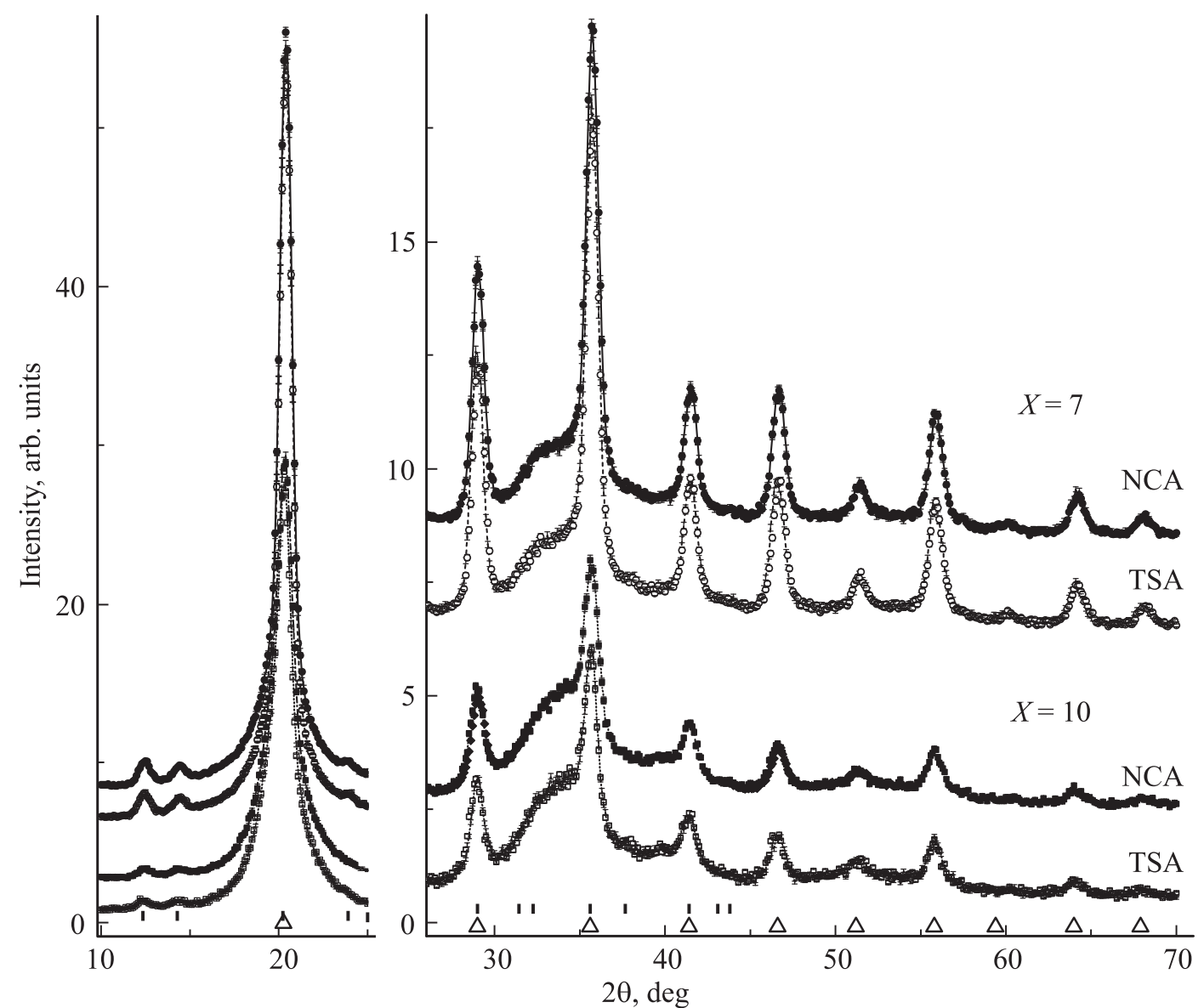

Рис. 6. Дифрактограммы образцов сплавов с $X=7$ и $X=10$, подвергнутых отжигу под нагрузкой (TSA) и без нее (NCA), разнесены по вертикали для наглядности. Треугольниками и вертикальными черточками показано расчетное положение пиков от ОЦК-решетки нанокристаллов и от областей с $D 0_{3}$ упорядочением соответственно. В правой части дифрактограммы масштаб шкалы интенсивности увеличен примерно в 2.6 раза.

тропии (анизотропии типа жесткая ось) в сплавах с содержанием кремния более $11 \%$ особое значение имеет присутствие фазы $\mathrm{Fe}_{3} \mathrm{Si}$. В дифрактограмме образца, отожженного без нагрузки, продольный и поперечный сканы совпадают. Остаточные деформации решетки нанокристаллов не наблюдаются. Параметр ОЦК-решетки нанокристаллов равен $0.283786(3)$ и $0.283774(3) \mathrm{nm}$ при $X=7$ и 10 соответственно. При $X=0$ параметр решетки нанокристаллов равен $0.28417(1) \mathrm{nm}$ [12]. Следовательно, при увеличении содержания хрома от 0 до 10\% параметр решетки уменьшается на $0.15 \%$. При переходе от 7 к 10\% хрома в сплаве параметр решетки меняется мало (или почти не меняется, если учитывать ошибку). Поэтому, пока остается не выясненным, входит ли хром в состав нанокристаллов после отжига или остается в аморфной матрице.

В дифрактограммах образцов сплава с $X=10$ (по сравнению с $X=7$ ) наблюдается существенное падение интенсивности основных пиков от ОЦК-решетки нанокристаллов на фоне широкого диффузного рассеяния от аморфной матрицы, что, конечно, является свидетельством уменьшения относительной объемной доли нанокристаллов в сплаве с $X=10$ после отжига при температуре $520^{\circ} \mathrm{C}$ в течение $2 \mathrm{~h}$. Это в равной мере относится к образцам, прошедшим отжиг под нагрузкой. Если диффузный фон от аморфной фазы в приведенных дифрактограммах примерно одинаковый, то интенсивность кристаллических пиков при $X=10$ в 2-3 раза меньше, чем при $X=7$. Скорее всего этот эффект связан с недостаточно высокой температурой отжига для полной нанокристаллизации при более высоком содержании хрома, что было отражено в изменениях хода кривых DTA, приведенных ранее в работе [3].

Для того чтобы увидеть разницу в дифрактограммах образцов, прошедших термическую обработку при разных условиях, необходимо рассмотреть профили отдельных пиков в дифрактограммах на рис. 6. Профили брэгговских пиков (200), (310) и (222) для двух образцов сплава с $X=7$ показаны на рис. 7. Как для образца, подвергнутого отжигу под нагрузкой, создающей растягивающее напряжение около $160 \mathrm{MPa}$, так и для образца, отожженного без внешних воздействий, на рисунке приведены профили из дифрактограмм, измеренных при продольном (вдоль ленты или вдоль 


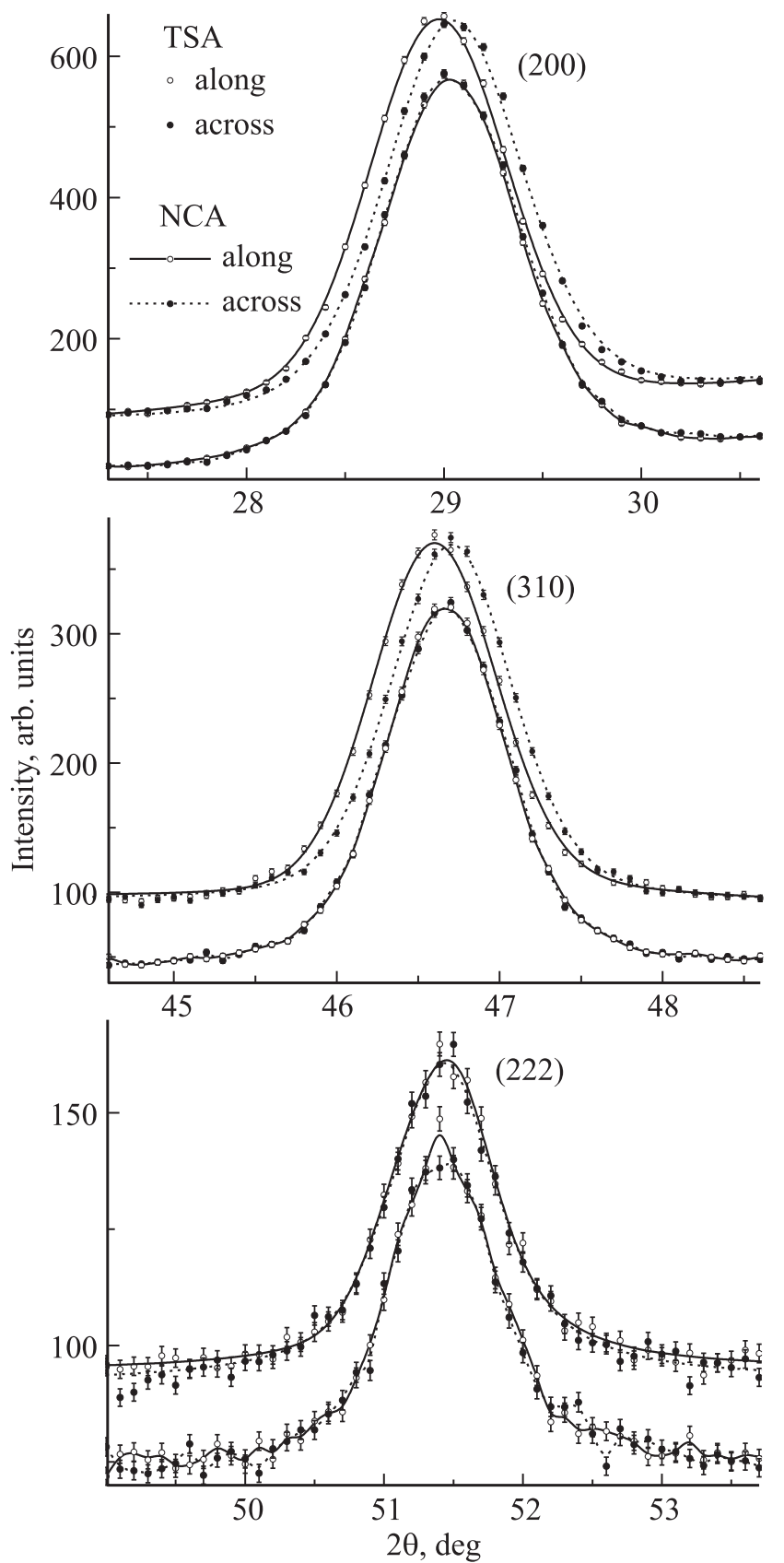

Рис. 7. Профили пиков (200), (310) и (222) в продольной (along) и поперечной (across) дифрактограммах образцов сплава, содержащего 7\% хрома, подвергнутых отжигу под нагрузкой (TSA) и отжигу без внешних воздействий (NCA), разнесены по вертикали для наглядности. Результаты МНК аппроксимации пиков функциями Войта показаны гладкими линиями: сплошной для продольного скана и штриховой для поперечного.

направления приложения нагрузки при ТМехО) и при поперечном сканировании. Видно, что после ТМехО в продольном скане пики (200) и (310) смещены в сторону меньших углов рассеяния, а в поперечном, наоборот, в сторону больших углов.
Небольшое смещение брэгговских пиков происходит из-за увеличения межплоскостного расстояния для плоскостей в решетке нанокристаллов, когда нормаль к ним ориентирована вдоль направления сканирования, т.е. вдоль направления приложения нагрузки при ТМехО. Поэтому вдоль ленты после ТМехО имеются растяжения решетки нанокристаллов, а поперек ленты - сжатия. Положение каждого отдельного пика определено из аппроксимации его профиля методом наименьших квадратов (МНК), подробное описание этой обычной для анализа дифрактограмм процедуры можно найти в работе [12]. Результаты МНК аппроксимации

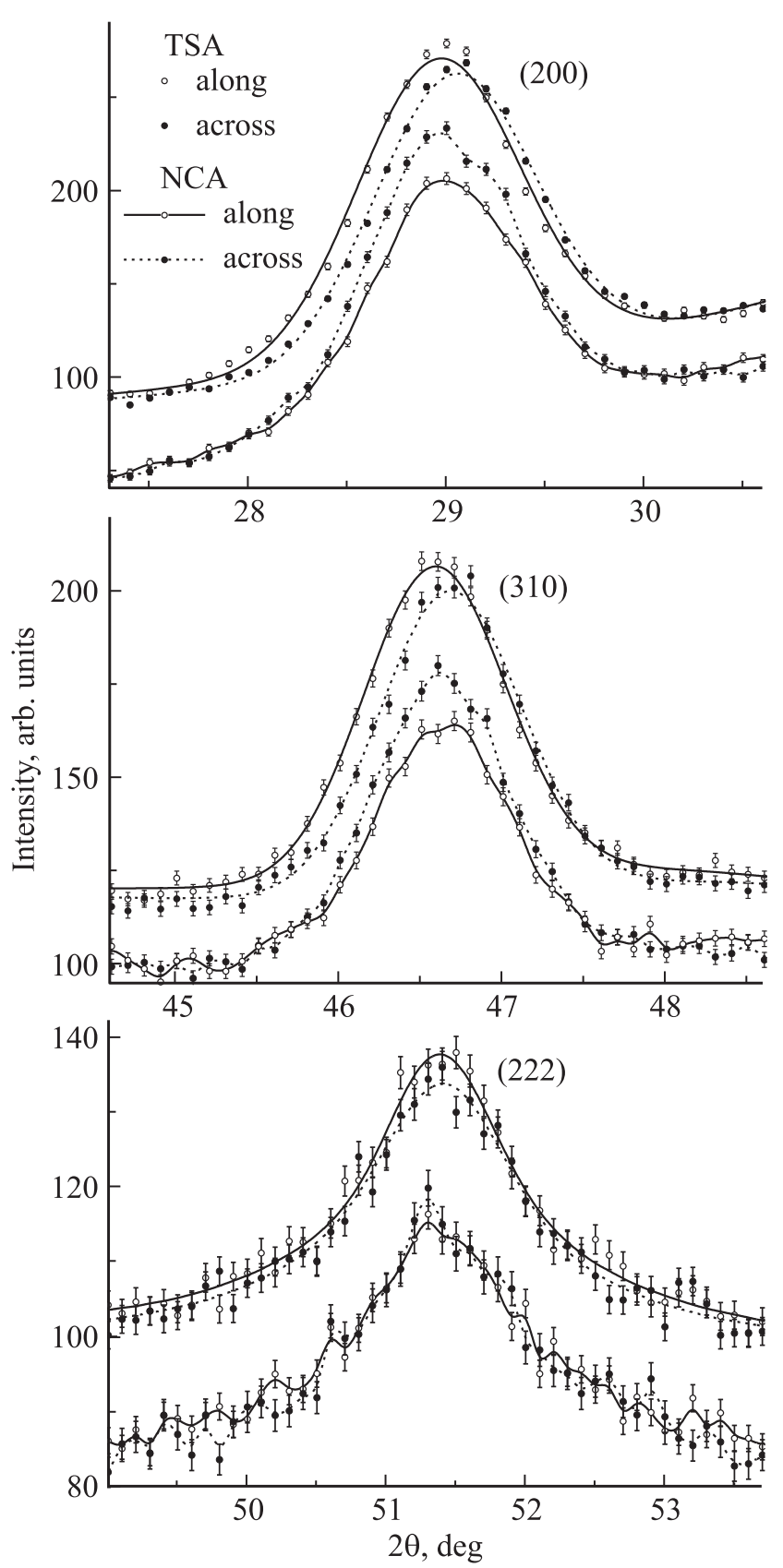

Рис. 8. То же, что на рис. 7 для образцов сплава, содержащего $10 \%$ хрома. 
показаны на рис. 7 гладкими линиями, а положение (угол $2 \theta$ ) пика (200) 28.91(1) ${ }^{\circ}$ в продольном и 28.99(1) ${ }^{\circ}$ в поперечном скане, (310) - 46.51(1) ${ }^{\circ}$ в продольном и $46.608(3)^{\circ}$ в поперечном скане, $(222)-51.33(1)^{\circ}$ в продольном скане и $51.32(1)^{\circ}$ в поперечном скане. Из разницы положений для каждого пика нетрудно вычислить изменение межплоскостного расстояния. Оно оказывается различным для разных кристаллографических направлений, что свидетельствует об анизотропии упругих свойств $\mathrm{Fe}-\mathrm{Si}$ нанокристаллов.

Аналогичный анализ профилей дифракционных пиков (200), (310) и (222) был выполнен и для образцов, содержащих $10 \%$ хрома. Соответствующие профили и результаты их МНК аппроксимации показаны на рис. 8,

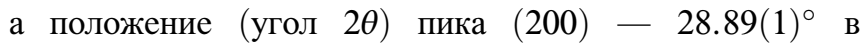
продольном и $28.97(1)^{\circ}$ в поперечном скане, (310) $46.50(1)^{\circ}$ в продольном и $46.59(1)^{\circ}$ в поперечном скане на дифрактограмме образца, подвергнутого отжигу под нагрузкой. При $X=10$ положение пика (222) $51.28(1)^{\circ}$ в продольном и $51.29(2)^{\circ}$ в поперечном скане, т.е. в пределах точности измерений они совпадают. Профили соответствующих пиков в дифрактограммах образца, прошедшего отжиг без внешних воздействий, немного различаются по интенсивности, но при этом по позициям всегда совпадают в пределах экспериментальной погрешности $\pm 0.01^{\circ}$.

Очевидно, что и другие брэгговские пики, которые видны на рентгеновских дифрактограммах, отмеченных TSA на рис. 6, должны смещаться аналогичным образом. Это и было показано ранее в работах $[12,13]$ для образцов сплавов $\mathrm{Fe}-\mathrm{Si}-\mathrm{Nb}-\mathrm{Cu}-\mathrm{B}$ с разным содержанием кремния, подвергнутых ТМехО при растягивающем напряжении в три-четыре раза большем, чем в настоящей работе для сплавов с хромом. Здесь же эффективное растягивающее напряжение $160 \mathrm{MPa} \mathrm{выбрано} \mathrm{таким,} \mathrm{как}$ в [4] и [5], поэтому в дифрактограммах на рис. 6 пики (110), (211), (220) и (321) смещены, но на величину, сравнимую с точностью измерений.

На рис. 9 показаны зависимости относительных деформаций $\varepsilon_{h k l}$ в разных кристаллографических направлениях $[h k l]$, рассчитанных по формуле (2), от угла $\Phi$ между направлением нормали к плоскости (222), (211), (321), (220), (310) или (200) и ближайшей осью $\langle 111\rangle$.

Максимальная величина деформации как растяжения, так и сжатия получена для плоскостей (200) - $\varepsilon_{200}$, несколько меньше - для (310) - $\varepsilon_{310}$. Поскольку деформации пропорциональны приложенному при отжиге напряжению $[9,20]$, то при его увеличении в два или три раза возрастет по абсолютной величине и $\varepsilon_{h k l}$ для всех $h k l$ кроме (222). Результаты многочисленных измерений, приведенные, например в работах $[8,11,12,20-22]$, показывают, что остаточная после ТМехО деформация $\varepsilon_{222}$ независимо от величины приложенного при отжиге напряжения вплоть до $600 \mathrm{MPa}$ в пределах ошибки измерений равна нулю. В связи с этим существует необходимость значительного повышения точности рентгендифракционных измерений, например за счет использо-

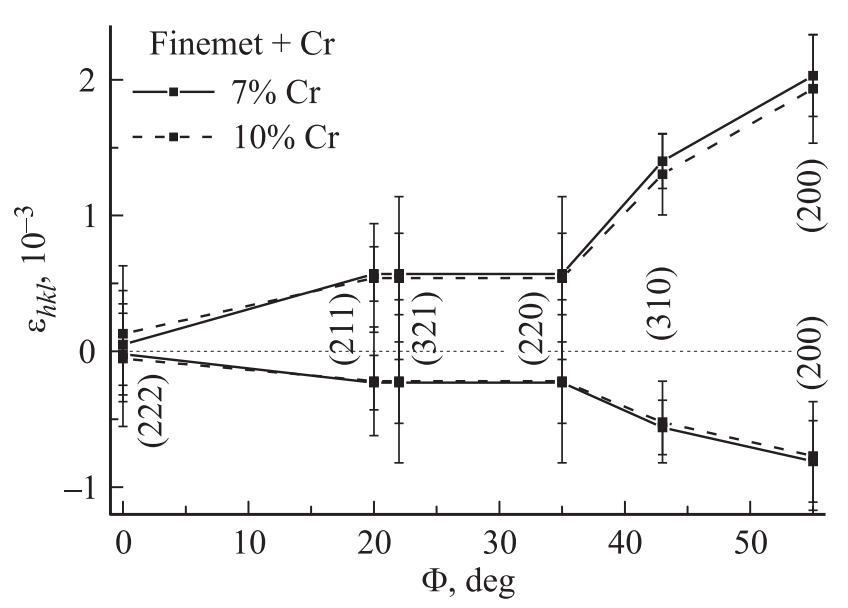

Рис. 9. Остаточная деформация решетки нанокристаллов после отжига под действием растягивающей нагрузки в образцах сплава файнмет с $X=7$ и 10.

вания дифрактометров, установленных на пучках синхротронного излучения, что позволит оценить влияние приложенного при ТМехО напряжения на деформирование решетки $\alpha$-FeSi нанокристаллов в наиболее жестком направлении $\langle 111\rangle$ и корректно определить величину модуля упругости вдоль других кристаллографических направлений [21,22].

Фазовый анализ дифрактограмм, приведенных на рис. 6, подразумевает определение вкладов отдельных фаз. Узкие интенсивные пики с четной суммой индексов $(h+k+l)$ представляют собой вклад в рассеяние от ОЦК-решетки нанокристаллов. Их положение показано треугольниками на рис. 6. Остальные более слабые, но тоже узкие пики - вклад в рассеяние от областей с $\mathrm{DO}_{3}$ упорядочением (фаза $\mathrm{Fe}_{3} \mathrm{Si}$ ). Их положение показано вертикальными черточками на рис. 6. Аморфная матрица, имеющая химический состав $\mathrm{Fe}(\mathrm{Nb})-\mathrm{B}$, дает вклад в осциллирующий фон, который формально и достаточно произвольно можно описать совокупностью широких пиков с формой гауссиана или лоренциана, расположенных на линейно зависящей от угла $2 \theta$ подставке (наклонный фон). На рис. 10 показана дифрактограмма образца с 7\% хрома, прошедшего отжиг без нагрузки, и ее разложение.

Поскольку число брэгговских пиков мало и большинство из них содержит вклад от ОЦК- и $\mathrm{DO}_{3}$-фаз, а фон имеет сложную осциллирующую форму, получить надежный результат разложения затруднительно. Поэтому основная цель разложения - получить качественный (полуколичественный) результат, т. е. понять тенденцию в изменении отношения интегральных интенсивностей брэгговских пиков ОЦК-фазы, $D 0_{3}$-фазы и пиков, описывающих фон, в зависимости от концентрации хрома и способа обработки образца. Узкие кристаллические пики аппроксимировались функциями Гаусса. Аналогичные разложения были сделаны для дифрактограмм, приведенных на рис. 6, и для дифрактограммы образца спла- 


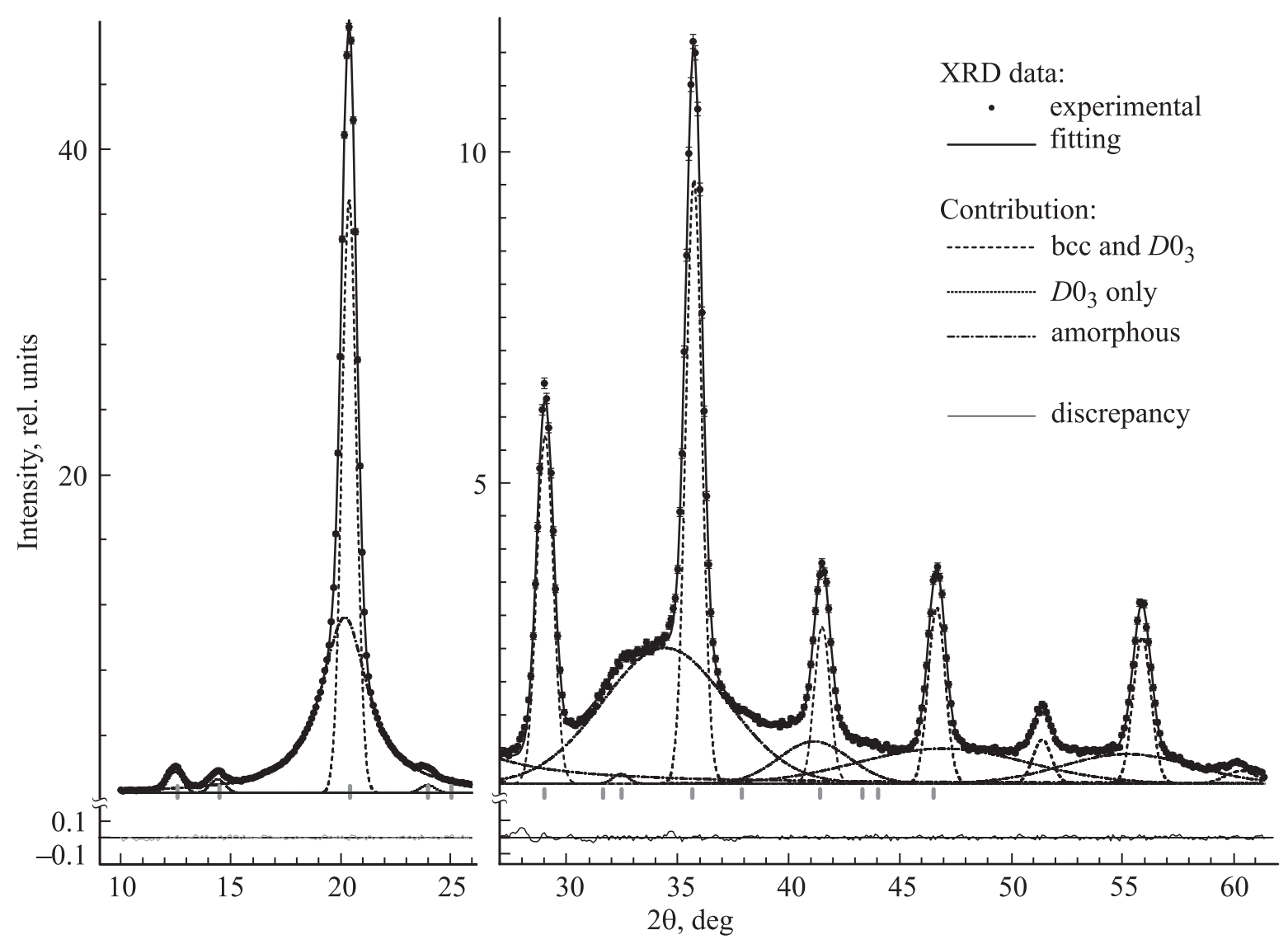

Рис. 10. Дифрактограмма образца с 7\% хрома, прошедшего отжиг без нагрузки, и ее разложение на отдельные пики. Фон описан формально совокупностью широких пиков. Под дифрактограммой показана разностная кривая между расчетными и экспериментальными точками - невязка. В правой части дифрактограммы масштаб шкалы интенсивности увеличен в 4 раза.

ва $\mathrm{Fe}_{73.5} \mathrm{Si}_{13.5} \mathrm{Nb}_{3} \mathrm{Cu}_{1} \mathrm{~B}_{9}$, прошедшего кристаллизующий отжиг без нагрузки при температуре $520^{\circ} \mathrm{C}$ в течение $2 \mathrm{~h}[12]$. Поскольку полученные при продольном и поперечном сканировании дифрактограммы образцов после нанокристаллизующего отжига без нагрузки полностью совпадают, то в таком случае разложению подвергалась их полусумма. Зная из разложения высоту и ширину каждого пика аморфной, ОЦК- и $D 0_{3}$-фаз, можно вычислить его интегральную интенсивность. Грубую оценку относительного вклада каждой из фаз можно получить из отношения суммарной интегральной интенсивности пиков $I_{\mathrm{NC}}$ от двух нанокристаллических фаз к суммарному вкладу от аморфной матрицы $I_{\text {matrix }}$ и отношения суммы интенсивностей $D 0_{3}$ пиков $I_{D 03}$ к $I_{\mathrm{NC}}$, которые приведены в табл. 2.

Для образцов после ТМехО в табл. 2 отдельно представлены отношения интенсивностей в дифрактограммах, измеренных при продольном и поперечном сканировании: строки 3 и 4 относятся к образцу сплава с $X=7$, а строки 6 и $7-$ к образцу с $X=10$ соответственно. Сравнение пар отношений, приведенных в строках 3 и 4, 6 и 7, показывает, что в пределах погрешности отношения интенсивностей $I_{\mathrm{NC}} / I_{\text {matrix }}$ и $I_{D 03} / I_{\mathrm{NC}}$ совпадают, и это вполне естественно, так как результаты фазового анализа не должны зависеть от направления сканирования при измерении дифрактограммы. При сопоставлении результатов фазового анализа для образцов, прошедших НО, с результатами для образцов после ТМехО, оказалось, что отношение $I_{\mathrm{NC}} / I_{\text {matrix }}$ после ТМехО при $X=7$ и при $X=10$ на $3-5 \%$ и на 7-10\% соответственно больше, чем после НО. Возможно, что в присутствии механического напряжения эффективность кристаллизующего отжига при одной и той же температуре и продолжительности повышается.

Отношения $I_{D 03} / I_{\mathrm{NC}}$ изменяются от 0.03 до 0.10 . Различие значений $I_{D 03} / I_{\mathrm{NC}}$ до трех раз, скорее всего, связано с тем, что слабые брэгговские пики ненадежно определяются на сильном фоне матрицы. Ранее в работе [12] оценка массовой доли $\mathrm{Fe}_{3} \mathrm{Si}$ фазы с использованием данных ЯГР-спектроскопии (эффект Мессбауэра) была сделана для сплава $\mathrm{Fe}_{73.5} \mathrm{Si}_{13.5} \mathrm{Nb}_{3} \mathrm{Cu}_{1} \mathrm{~B}_{9}$ после нанокристаллизации. Анализ интенсивностей линий от разных локальных окружений атомов железа показал, что области с $\mathrm{DO}_{3}$ упорядочением занимают до $80 \%$ объема $\mathrm{Fe}-\mathrm{Si}$ нанокристаллов. Отношение $I_{D 03} / I_{\mathrm{NC}}$ в дифрактограммах образцов с хромом больше, чем в дифрактограмме образца сплава, не содержащего хром. 
Таблица 2. Отношения суммарных интегральных интенсивностей вкладов от двух нанокристаллических (NC), аморфной (matrix) и $D 0_{3}-(D 03)$-фаз в рентгеновских дифрактограммах образцов сплавов без хрома, с 7 и $10 \%$ хрома, прошедших кристаллизующий отжиг без внешних воздействий $(\mathrm{HO})$ и отжиг под растягивающей нагрузкой (ТMехО)

\begin{tabular}{|c|c|c|c|c|c|}
\hline \multirow{2}{*}{$\begin{array}{l}\text { № } \\
\Pi / \Pi\end{array}$} & \multirow{2}{*}{$\begin{array}{l}C_{\mathrm{Cr}}, \\
\text { at. } \%\end{array}$} & \multirow{2}{*}{$\begin{array}{c}\text { Термо- } \\
\text { обработка }\end{array}$} & \multirow{2}{*}{$\begin{array}{l}\text { Направление } \\
\text { сканирования }\end{array}$} & \multicolumn{2}{|c|}{ Отношения интенсивностей } \\
\hline & & & & $I_{\mathrm{NC}} / I_{\text {matrix }}$ & $I_{D 03} / I_{\mathrm{NC}}$ \\
\hline 1 & 0 & $\mathrm{HO}(\mathrm{NCA})$ & любое & $1.358 \pm 0.014$ & $0.0306 \pm 0.0011$ \\
\hline 2 & \multirow{3}{*}{7} & $\mathrm{HO}(\mathrm{NCA})$ & любое & $1.178 \pm 0.005$ & $0.0440 \pm 0.0005$ \\
\hline 3 & & \multirow{2}{*}{ TMexO (TSA) } & вдоль & $1.218 \pm 0.008$ & $0.0410 \pm 0.0009$ \\
\hline 4 & & & поперек & $1.235 \pm 0.013$ & $0.0392 \pm 0.0009$ \\
\hline 5 & \multirow{3}{*}{10} & $\mathrm{HO}(\mathrm{NCA})$ & любое & $0.337 \pm 0.003$ & $0.1007 \pm 0.0018$ \\
\hline 6 & & \multirow{2}{*}{ TMexO (TSA) } & вдоль & $0.361 \pm 0.003$ & $0.0441 \pm 0.0013$ \\
\hline 7 & & & поперек & $0.369 \pm 0.004$ & $0.0444 \pm 0.0017$ \\
\hline
\end{tabular}

Это означает, что и в нанокристаллах сплавов с хромом присутствует большая доля областей, упорядоченных по $D 0_{3}$-типу, независимо от условий кристаллизующего

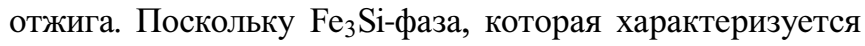
отрицательным магнитоупругим взаимодействием, является ответственной за наведение поперечной магнитной анизотропии типа жесткая ось в $\mathrm{Fe}-\mathrm{Si}-\mathrm{Nb}-\mathrm{Cu}-\mathrm{B}$ сплавах с содержанием кремния $11-13.5 \%$ под влиянием остаточных деформаций решетки нанокристаллов, образующихся в результате ТМехО, то и в сплавах, легированных хромом, скорее всего реализуется аналогичный механизм формирования поперечной магнитной анизотропии при отжиге под нагрузкой, подробно описанный в [12].

О корреляции магнитных свойств с изменениями структуры свидетельствуют графики, приведенные на рис. 11 из которых видно, что максимальная индукция $B_{m}$ и отношение интенсивностей $I_{\mathrm{NC}} / I_{\text {matrix }}$ для

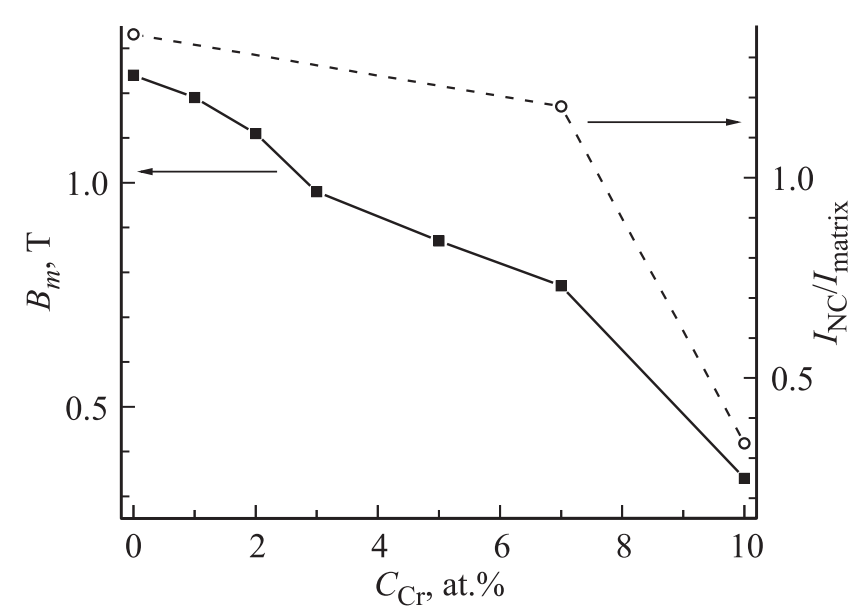

Рис. 11. Зависимость максимальной индукции $B_{m}$ и отношения интенсивностей $I_{\mathrm{NC}} / I_{\text {matrix }}$ от концентрации хрома в сплаве. образцов, отожженных при температуре $520^{\circ} \mathrm{C}$, резко уменьшаются при увеличении концентрации хрома от 7 до 10\%. Это обусловлено тем, что температура отжига недостаточна для формирования максимального количества нанокристаллов при концентрации хрома $10 \%$, но ведь как раз массовой доле нанокристаллов в сплаве после $\mathrm{HO}$ и ТМехО и пропорциональна максимальная индукция. Действительно, максимальная магнитная индукция $B_{m}$ увеличивается до $0.60 \mathrm{~T}$ при повышении температуры отжига до $600^{\circ} \mathrm{C}$, что видно и в табл. 1, и по изменению петли гистерезиса на рис. $1, g-h$. Структурные исследования образцов сплава $\mathrm{Fe}-\mathrm{Si}-\mathrm{Nb}-\mathrm{Cu}-\mathrm{B}$, легированного хромом, отожженных при температуре $600^{\circ} \mathrm{C}$, до сих пор не проводились.

\section{4. Заключение}

Исследовано влияние отжига под растягивающей нагрузкой на магнитные свойства и структуру типичных файнмет сплавов $\mathrm{Fe}_{73.5} \mathrm{Si}_{13.5} \mathrm{Nb}_{3} \mathrm{Cu}_{1} \mathrm{~B}_{9}$, легированных хромом за счет железа. Образцы сплавов были получены в виде тонких лент закалкой из расплава, которые затем подвергались кристаллизующему отжигу при температуре $520^{\circ} \mathrm{C}$ в течение $2 \mathrm{~h}$. Отжиг производился как под действием растягивающей нагрузки, которая создавала напряжение около $160 \mathrm{MPa}$, так и без нее.

Для наблюдения за изменениями магнитных свойств измерялись статические петли магнитного гистерезиса, из которых определялись такие параметры, как магнитная индукция, коэрцитивная сила и константа наведенной магнитной анизотропии. Структура сплавов исследовалась методом рентгеновской дифракции в геометрии на просвет, при этом вектор рассеяния всегда оставался в плоскости тонкой ленты. Для каждого из образцов измерялись две дифрактограммы, одна при направлении вектора рассеяния вдоль ленты, а вторая - поперек ленты, т.е. вдоль и поперек направления приложения 
нагрузки при ТМехО. По положениям узких дифракционных линий от нанокристаллов определялись параметры ОЦК-решетки нанокристаллов и ее остаточные деформации, т.е. изменение межплоскостных расстояний после отжига под нагрузкой. Для грубой оценки фазового состава образцов сплава проводилось разложение дифрактограмм методом наименьших квадратов на вклады от нанокристаллов и аморфной матрицы.

В результате проведенных исследований показано, что легирование сплава файнмет хромом приводит к монотонному снижению максимальной намагниченности. В интервале от 0 до 7\% хрома уменьшение $B_{m}$ составляет около $5.5 \%$ на $1 \%$ немагнитного хрома, а между 7 и $10 \%$ достигает $12 \%$ на $1 \%$ Cr. Если кристаллизация сплава с 10\% хрома происходит при повышенной до $600^{\circ} \mathrm{C}$ температуре, то максимальная индукция может быть увеличена до $53 \%$ от $B_{m}$ сплава без хрома. В этом случае среднее уменьшение величины максимальной индукции на интервале концентрации хрома от 0 до 10\% составляет около 5\% на один процент хрома.

Коэрцитивная сила, относительно низкая в интервале концентраций хрома от 0 до $3 \%$, увеличивается в несколько раз при $X=5$, затем дважды - примерно на порядок при достижении $X=7$ и при достижении $X=10$. Предполагается [23], что это связано с изменениями магнитных свойств аморфной матрицы. Постепенно она передает магнитное взаимодействие между нанокристаллами все хуже, потому что по мере увеличения в ней содержания хрома понижается ее температура Кюри и матрица переходит в парамагнитное состояние при температуре магнитных измерений $20^{\circ} \mathrm{C}$.

Термомеханическая обработка, отжиг под нагрузкой, эффективно влияет на магнитные свойства сплава $\mathrm{Fe}_{73.5-x} \mathrm{Si}_{13.5} \mathrm{Cr}_{X} \mathrm{Nb}_{3} \mathrm{Cu}_{1} \mathrm{~B}_{9}$ при всех значениях $X$ от 0 до 10. Петли магнитного гистерезиса принимают наклонную форму, перемагничивание вдоль ленты становится затруднительным, наводится поперечная магнитная анизотропия типа жесткая ось. В результате ТМехО существенно меняются параметры, полученные из измерений при перемагничивании вдоль ленты. Остаточная намагниченность, $B_{r}$, уменьшается от нескольких десятых до нескольких сотых Tesla, величина магнитного поля насыщения, $H_{s}$, увеличивается на два порядка. Константа магнитной анизотропии, $K_{u}$, наведенной в поле механического напряжения в $160 \mathrm{MPa}$, при $X=0-2$ достигает величины - $(1600-1700) \mathrm{J} / \mathrm{m}^{3}$, затем уменьшается до $-950 \mathrm{~J} / \mathrm{m}^{3}$ при $X=7$ и резко падает до $-180 \mathrm{~J} / \mathrm{m}^{3}$ при $X=10$.

В решетке нанокристаллов после ТМехО наблюдается остаточная деформация: если кристаллографические направления [200] и [310] совпадают с осью ленты, то межплоскостные расстояния увеличены на 0.2 и $0.14 \%$ соответственно, а если они перпендикулярны оси ленты, то расстояния уменьшены на 0.08 и $0.056 \%$, что в несколько раз превышает погрешность измерений. Приведенные значения относительного изменения межплоскостных расстояний соответствуют величине приложенного при
ТМехО-напряжения [11]. Деформация вдоль направлений [211], [220] и [321] не превосходит экспериментальную ошибку. Изменения межплоскостного расстояния для (222) не зафиксировано. Из вышесказанного следует, что остаточные деформации решетки нанокристаллов анизотропны, а объясняется это анизотропией упругих свойств ОЦК-решетки $\mathrm{Fe}(\mathrm{Si})$ нанокристаллов [10].

Наблюдаемые остаточные деформации в решетке нанокристаллов благодаря магнитоупругому эффекту Виллари приводят к возникновению поперечной магнитной анизотропии в лентах сплава $\mathrm{Fe}_{73.5} \mathrm{Si}_{13.5} \mathrm{Nb}_{3} \mathrm{Cu}_{1} \mathrm{~B}_{9}[10,12]$. При этом тип анизотропии обусловлен присутствием в нанокристаллах большой объемной доли фазы с упорядочением типа $\mathrm{Fe}_{3} \mathrm{Si}$, для которой характерно отрицательное магнитоупругое взаимодействие. Легирование хромом не оказывает влияния на тип магнитной анизотропии, наводимой при отжиге под нагрузкой в ленточных образцах сплава, потому что в сплавах с хромом в нанокристаллах имеет место сочетание остаточных деформаций с большой долей фазы $\mathrm{Fe}_{3} \mathrm{Si}$.

Добавление хрома в сплав $\mathrm{Fe}_{73.5} \mathrm{Si}_{13.5} \mathrm{Nb}_{3} \mathrm{Cu}_{1} \mathrm{~B}_{9}$ понижает объемную долю нанокристаллов, образующихся при отжиге в течение $2 \mathrm{~h}$ при температуре $520^{\circ} \mathrm{C}$. Если при концентрации $\mathrm{Cr} 7 \%$ в зависимости от режима термообработки доля нанокристаллов снижается на $10-14 \%$, то при $10 \% \mathrm{Cr}-$ на $73-77 \%$, что находится в соответствии с резким снижением магнитной индукции при переходе от сплавов с 7\% к сплавам с 10\% хрома. При этом доля нанокристаллов на несколько процентов больше после отжига под действием растягивающего напряжения, чем после отжига без нагрузки. Возможно, что внешнее напряжение является дополнительным активатором процесса кристаллизации сплавов типа файнмет, но этот момент требует дополнительных детальных исследований.

\section{Список литературы}

[1] Y. Yoshizawa, S. Oguna, K. Yamauchi. J. Appl. Phys. 64, 6044 (1988).

[2] F.F. Marzo, A. Altube, A.R. Pierna. Electrochimica Acta 47, 2265 (2002).

[3] N. Chau, P.Q. Thanh, N.Q. Hoa. JMMM 304, 36 (2006).

[4] S.O. Volchkov, V.A. Lukshina, A.A. Zakharova, A.P. Potapov, E.G. Volkova. IEEE Trans. Magn. 50, 11, 4007504 (2014).

[5] V.A. Lukshina, N.V. Dmitrieva, M.A. Cerdeira, A.P. Potapov. J. Alloys Comp. 536S, S374 (2012).

[6] G.V. Kurlyandskaya, V.A. Lukshina, A. Larranaga, I. Orue, A.A. Zaharova D.A. Shishkin. J. Alloys Comp. 566, 31 (2013). DOI:10.1016/j.jallcom.2013.03.006

[7] A. Zeleňáková, J. Füzer, P. Kollár, M. Kužmiński. JMMM 304, e528 (2006).

[8] M. Ohnuma, K. Hono, T. Yanai, H. Fukunaga, Y. Yoshizawa. Appl. Phys. Lett. 83, 2859 (2003).

[9] M. Ohnuma, K. Hono, T. Yanai, M. Nakano, H. Fukunaga, Y. Yoshizawa. Appl. Phys. Lett. 86, 152513-1 (2005). 
[10] Ю.П. Черненков, Н.В. Ершов, В.И. Федоров, В.А. Лукшина, А.П. Потапов. ФТТ 52, 3, 514 (2010).

[11] M. Ohnuma, T. Yanai, K. Hono, M. Nakano, H. Fukunaga, Y. Yoshizawa, G. Herzer. J. Appl. Phys. 108, 093927-1 (2010).

[12] N.V. Ershov, Yu.P. Chernenkov, V.I. Fedorov, V.A. Lukshina, N.M. Kleinerman, V.V. Serikov, A.P. Potapov, N.K. Yurchenko. In: Nanocrystal. InTech, Rijeka (2011). P. 415-436.

[13] Н.В. Ершов, Н.В. Дмитриева, Ю.П. Черненков, В.А. Лукшина, В.И. Федоров, А.П. Потапов. ФТТ 54, 9, 1705 (2012).

[14] В.В. Сериков, Н.М. Клейнерман, Е.Г. Волкова, В.А. Лукшина, А.П. Потапов, А.В. Свалов. ФММ 102, 3, 290 (2006).

[15] G. Herzer, V. Budinsky, C. Polak. Phys. Status Solidi B 248, 10, 2382 (2011).

[16] Yu.A. Babanov, N.V. Ershov, V.R. Shvetsov, A.V. Serikov, A.L. Ageev, V.V. Vasin. J. Non-Cryst. Solids 79, 1-2, 1 (1986).

[17] H. Fischer, A. Barnes, P. Salmon. Rep. Prog. Phys. 69, 1, 233 (2006).

[18] B.E. Warren. X-ray diffraction. Addison-Wesley, N.Y. (1969). $563 \mathrm{p}$.

[19] G. Herzer. Handbook of Magnetic Materials / Ed. K.H.J. Buschow. Elsevier Science, N.Y. (1997). V. 10. Ch. 3. P. 415.

[20] Н.В. Ершов, В.А. Лукшина, В.И. Федоров, Н.В. Дмитриева, Ю.П. Черненков, А.П. Потапов. ФТТ 55, 3, 460 (2013).

[21] Н.В. Ершов, Ю.П. Черненков, В.И. Федоров, В.А. Лукшина, А.П. Потапов. ФТТ 56, 11, 2146 (2014).

[22] Н.В. Ершов, Ю.П. Черненков, В.И. Федоров, В.А. Лукшина, А.П. Потапов. ФТТ 57, 1, 7 (2015).

[23] V. Franco, C.F. Conde, A. Condea, L.F. Kiss, D. Kaptas, T. Kemeny, I. Vincze. J. Appl. Phys. 90, 3, 1558 (2001). 